\title{
WEAK LINKS IN THE CHAIN OF COMPARATIVE ADVA"'TAGE
}

\author{
Alan V. DEARDCRFF* \\ Institute for International Economic Studies, Univerity of Stockholm, Stockholm. Sweden \\ University of Michigan, Ann Arbor, MI 48109, USA
}

Received October 1978

This paper examines the proposition that trade in many commodities can be explained by a chain of comparative advantage. It is first shown, in a two-country, two-factor model, that trade accords win the ranking of goods by factor intensity if there are unequal factor prices, free trade, and only final goods. This result continues to hold if either trade impediments or intermediate products are introduced. However, if both are present, the chain proposition breaks down. Fnally, with many countries, it is shown that trade impediments alone can invalidate the chain proposition.

\section{Introduction}

My purpose in this paper is to investigate the froposition that trade in many commodities can be understood by first ranking the goods in order of factor intensities, then showing that all of a country's exports must lie higher on this list than all of its imports. A similar idea of a chain of comparative advantage was shown by Haberler (1936, p. 137) to be valid in a manycommodity extension of the classical theory of trade, the rankings there being of course in terms of comparative costs. The proposition was also stated for a two-factor, two-country version of the Heckscher-Ohlin model by Jones (1956-57), but was shown by Bhagwati (1972) to be incorrest if factor prices are equalized. Jones and Bhagwati apparently concurred, however, that the proposition would be valid whenever factor prices are not equalized, though neither provided a proof. Since a prime cause of unequal factor prices is the existence of tariffs, and since Travis $(1964,1972)$ has claimed that protection can account for the Leontief paradox, presumably $t y$

*I would like to thank Jagdish Bhagwati, Ronald Jones, Richard Porter, Robert Stern and members of the Research Seminar in International Economics, University of Michigan, for their helpful comments. 
altering the pattern of trade, ${ }^{1}$ it seems that a concensus has not yet been reached as to just how general the chain-of-comparative-advantage idea is. In what follows, I explore the matter further and show that these differences of opinion can be reconciled.

Specifically, I show first that Jones and Bhagwati were right, so long as we remain in the model that they were considering, which excludes the possibility of produced goods being used as intermediate factors of production. That is, I will demonstate the chain proposition in such a model whenever factor prices are unequal, whether that inequality is the result of complete specialization un in impediments to trade (section 2) or of tariffs and transport costs (sectica 3). Then I will introduce intermediate goods. This modification, it turns oul, does not invalidate the chain proposition so long as there are unequal factor prices and free trade (section 4). But when impediments to trade are added as well, the chain proposition collapses. For 1 show, in section 5 , that an increase iil a tariff can cause a good that was previously exported to become imported and, at the same time, a good that was previously imported to become exported. It follows that no ranking of the goods is possible, on the basis of factor intensities, autarky prices, or anything else, that will permit separation of exports and imports via a single break in the chain.

It is ironic that Jones, Bhagwati, and others have found comfort in the presence of transport costs aid other impediments to trade, which prevent factor-price equalization and inus remove the indeterminacy of production and trade: For the example in section 5 shows that, when there are intermediate goods, these same impediments to trade can invalidate the chain proposition when it would otberwise hold.

In the two-factor wald considered here, the chain proposition is related to, but not identical $\mathrm{i}$, , the Heckscher-Ohlin theorem. The former merely says that some ranking of goods exists which suffices to determine trade. The latter say's that the appropriate ranking is by factor intensities and, furthermore, that relative factor endowments determine which end of the chain contains a country's exports. However, in the cases considered here, the two propositions stand or fall together, so long as the price definition of factor abundance is used in stating the Heckscher-Ohlin theorem. For I will show in sections 2-4 that a country in which capital is relatively cheap, with trade, must export more capital intensive goods than it imports. And it can be shown, if there are only two countries, that relative factor prices must bear the same relationship with trade as without, so long as trade impediments

\footnotetext{
'Actually, it is difficult to be sure exactly what Travis was saying. He has never, to my knowledge, provided an example of a tariff that reverses the pattern of trade, though such an example is possible, as I show below in section 5. Nor is it clear whether Travis meant his remarks to be valid in a model of only iwo primary factors. In his (1972) article, he used and vigorously defended the two-factor assu ption, but concluded that, if tariffs are high enough, the bulk of trade will be: in goods requiring other primary factors.
} 
are non-negative. ${ }^{2}$ Thus, these sections also demonstrate the HeckscherOhlin theorem: that a country in which capital is relatively cheap in autarky must export relatively capital intensive goods. Also, of course, the counter example of section 5 shows that both propositions fail when there are both tra de impediments and intermediate goods.

'While most of the argument will be confined to a two-country world, it is of some interest also to show how the chain idea may extend to a world of many countries. This is not difficult, with the tools available, and, in section 6 , sho $\%$ that the chain of comparative advantage can be broken into several segments, one for each courtry. With the countries arranged along the chain in the same order as their relative factor endowments, each country will then export only goods within its segment of the chain and will import all others. That is true, however, only if tride is free and factor prices are unequal. Without the need, in this case, for intermediate goods, I will also show that tariffs can cause a rather dramatic rearrangement of the pattern of trade.

Considering the obvious importance, in the real world, of both trade impediments and intermediate goods. the results of this paper may seem to cast doubt on both the Heckscher-Ohlin theory and on the concept of comparative advantage itself. I therefore conclude in section 7 with a discussion of these more fundamental problems.

\section{Free trade}

Consider two countries, $\mathrm{A}$ and $\mathrm{B}$, producing and trading $n$ goods with no impediments to trade between them, so that the prices of the goods, $p_{1}, \ldots, p_{n}$, are the same in both countries. Production of each good requires the use of only two factors of production, capital $(K)$ and labor $(L)$, which ure nontraded and available in each country in fixed supply. Production functions are identical between countries, and have the usual propurties of concavity and homogeneity. Assume further that the goods can be ranked unambiguously in terms of capial intensity, $X_{1}$ being the most capital intensive and $X_{n}$, the least. Thus. there are no factor-intensity reversa!s between any pair of goods, and isoquants of different goods can intersect only once. Assume finally that perfect competition prevails in both countries,

\footnotetext{
${ }^{2}$ To see this, let $t$ be a vector of ad valcrem tariffs cum transport costs for each industry. Given technology, tastes, and factor endowments, the difference between the two countries factor-price ratios, $\Omega=\omega^{\mathrm{A}}-\omega^{\mathrm{B}}$, must be a continuous function of $t, \Omega(t)$. Let $t^{0}$ be a particular vector of non-negative trade impedir.ents, lit $t^{a}$ be a vector that would prevent trade entirely. and suppose that $\Omega\left(t^{0}\right)>0$ (as in fig. 1 below) yet $\Omega\left(t^{a}\right)<0$. Then by continuity there exis:s $t^{\prime}>0$ such that $Q\left(t^{\prime}\right)=0$ and such that irade takes place. But if $\Omega=0$, 1 hen factor prices are equal and so are commodity prices, and it is imposible for trade to ake place over pusitive trade impediments, $t^{\prime}>0$. From this contradiction it follows that $\Omega\left(t^{a}\right) \geqq 0$. Since $\Omega\left(t^{a}\right)=0$ can also be ruled out as implying that $\Omega(t)=0$ for all $t$, it follows that $\Omega\left(t^{0}\right)>0$ implies $\Omega\left(t^{a}\right)>0$.
} 
so that price equals average cost for any good that is produced and is less than or equal to average cost for any good that is not produced.

Suppose now that all that is known about a free trade equilibrium is that particular and unequal factor prices prevail in the two countries. What does this imply about the pattern of trade?

Begin by drawing the unit isocost lines for the two countries. These are shown in fig. 1 as the lines $A A^{\prime}$ for country $\mathrm{A}$ and $B B^{\prime}$ for country $\mathrm{B}$, and represent the combinations of capital and labor which would cost, say, one dollar (or other international numeraire) in each of the two countries. They are shown as intersecting at a point $M$, with country A depicted as having a higher ratio of wage to rental $(\omega)$ than country B. ${ }^{3}$

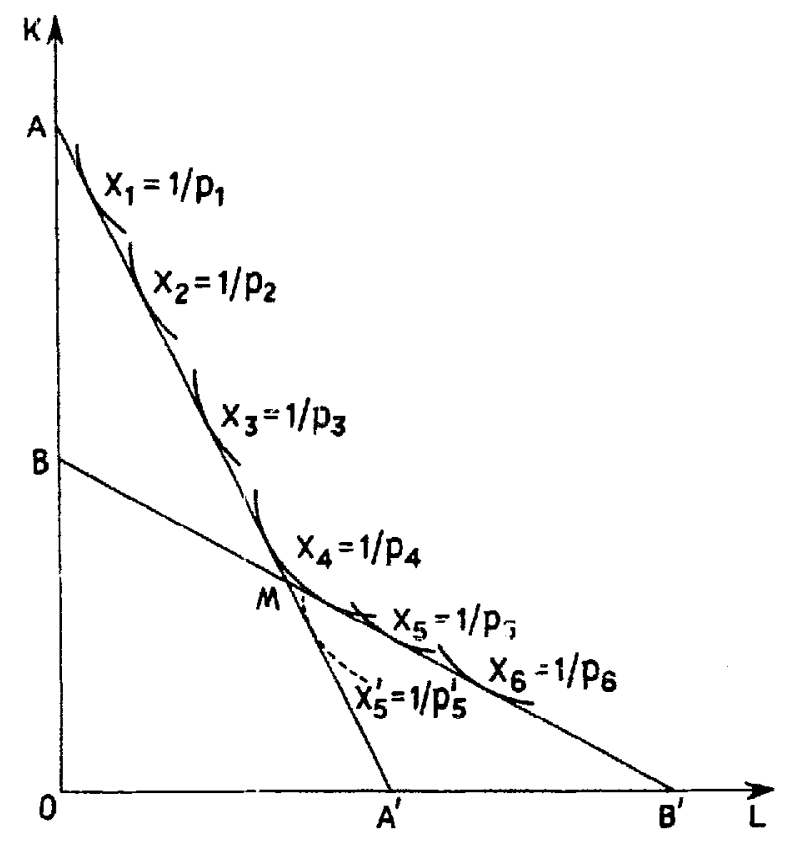

Fig. 1

From these isocost lines one can conclude what the free trade prices of each gocd must be. That is, the price of each good must be such as to place its unit-value isoquant exactly tangent to the outermost of the two unitisocost lines, as shown by the (solid) isoquants drawn in fig. 1. For if a unitvalue isoquant were to lie wholly outside both $A A^{\prime}$ and $B B^{\prime}$, the good would not be produced in either country, while if it lay anywhere inside either one of the lines, its production would yield a positive profit in the corresponding country. Furthermore, while it is possible for an isoquant to be tangent to

\footnotetext{
${ }^{3}$ Unequai factor prices do not, of course, ensure that the two isocost lines will intersect, as drawn, since one could lie wholly outside the other. In that case, as the analysis below indicates, the chain proposition holds trivially since all goods will be exported by tiic same country. Were halanced trade assumed, sisch a situation would of course be excluded.
} 
both isocost lines (as good 4 in fig. 1), this need not happen for any good and, without factor intensity reversals, cannot happen for more than one.

It is now immediately evident from fig. 1 that the pattern of trade must agree with the ranking of the goods by factor intensity. The most capital intensive goods $(1,2$, and 3 in fig. 1) can only be produced in the high wage country, A, and must therefore be exported by $A$, while the most lahoi intensive (5 and 6 ) must be produced and exported by B. Good 4, in this case, may be produced in boih countries and may be exported by either. It therefore constitutes the division of the chain of comparative advantage.

We have already noted that the high relative wage in A implies that it is capital abundant by the price definition. ${ }^{4}$ It is also true in this case that $\mathrm{A}$ must be capital abundant by the physical definition as well. For we can see in fig. 1 that all production in A requires a higher ratio of capital to labor than all production in $B$. Thus, our result implies that every export of the capital abundant country, by either definition, must be more capital intensive than every one of its imports. ${ }^{5}$

Before exiending this analysis to include tariffs, transport costs, and intermediate goods, it should be pointed out that the technique used here does not derive the trade equilibrium. Rather, it assumes that an equilibrium exists and merely examines a particular property of that equilibrium. Much more information would be needed to determine, for example, what the equilibrium factor prices should be and where, in the chain of comparative advantage, the division between the two countries should be located.

\section{Impeded trade}

If tariffs or transport costs permit different prices in the two countries, then the argument as given above is no longer valid, for there will be different unit-value isoquants in the two countries. But the argument can easily be salvaged if direct subsidies to trade are not permitted. For then a good will be exported only if its price is at least as high abroad as at home, and imported only if its price is at least as low abroad as at home, to compensate exporters and importers for the additional cost of tariffs and transport. $^{6}$

\footnotetext{
${ }^{4}$ See footnote 2 .

${ }^{5}$ Rather remarkably, no assumption has been needed about demand or about relative factor prices in auta:ky. However, if demand were so biased as to make the autarky relati re wage in $A$ less than the autarky relative wage in $\mathrm{B}$, then factor prices would have to be equalized by free trade and the factor prices assumed in fig. 1 could not arise. This also follows from the argument given in footnote 2 .

${ }^{\text {In }}$ another context I have cailed this the assumption of 'natural' trade [see Deardorff (1977)]. This formulation is consistent with any of a variety of explicil assumptions about the nature of transport costs, so long as these sosts are non-negative. However, the reader may prefer to think of a more explicit assumption, stis as that of Samuelson (1954), who let a certain fraction of each good be used up in transport.
} 
To see how this works, consider again the two countries whose unit isocost lines, with trade, are those shown in fig. 1. Suppose that some good, $X_{i}$, is exported by country $\mathrm{A}$. To be exported it must be produced, and thus the unit-value isoquant of $X_{i}$ in $\mathrm{A}$ must be tangent to $A A^{\prime}$. Suppose it were tangent below the intersection $M$, like the dotted isoquant $X_{5}^{\prime}$ in fig. 1 . For the good to be exported from $\mathrm{A}$, it must also fetch at least as high a price in E (to cover any transport cost or tariff) and this would place B's unit-value isoquant for the same good still closer to the origin than $X_{5}^{\prime}$ and certainly inside the line $B B^{\prime}$. The good would then yield a positive profit in $B$, and this is impossible. Thus, the unit-value isoquants of all of A's exports must be tangent to $A A^{\prime}$ above its intersection with $B B^{\prime}$ exactly as was the case with free trade. Applying a similar argument $t$ exports from $B$, it follows as before that all of A's exports must be mors capital intensive than all of A's imports.

This then validates the Bhagwati-lones conjecture that a capital abundant country (using the price definition of abundance) will export only goods which are more capital intensive than any of its imports, if there are impediments to trade and unequal facior prices. ${ }^{7.8}$

\section{Interm ediate goods and free trade}

Now suppose that any or all of goods $1, \ldots, n$ can be used as intermediate inputs in production. The argument of section 2 with free trade remains intact if unit-value isoquants are replaced by unit-value-added isoquants.

For any good $X_{i}$, let the production function be given by

$$
X_{i}=F^{i}\left(K_{i}, L_{i}, X_{1 i}, \ldots, X_{n i}\right) \text {, }
$$

${ }^{7}$ Note that if trade impediments were positive for all goods, then the qualification that factor prices be unequal would be unnecessary. For equal factor prices would mean equal commodity prices and thus no trade.

${ }^{8}$ I have called this a istigture because I do not regard the ar zument provided by Bhagwati (1972) to be 2 proof, though naturally when a proposition is valid there can be some disarreement as to what constitutes proof. Bhagwati (p. 1054) argued that

... while a conmodity in the middle of a chain of exportables may be priced out of the export market in'o being a nontraded good by high transportation costs, it is impossible for it to be turned int-) an imported good.

Now it is certainly true that the cost of transporting a given exportable cannot cause it to be imported. But I see no a priori reason why the cost of transporting some other good might not cause this to happen. Suppose, for example, that the cost of importing eggs were to raise their price so high as to cause substitution away from both bacon and eggs towards oatmeal. Then oatmeal could become imported and bacon exported, even if the reverse would be true if eggs could be imported cheaply. The proof in the text shows that this cannot happen in a two-factor model (where chickens and pigs - or the farmers that raise them - could be employed planting ouis), but 1 see nothing in Bhagwati's remarks to rule this out. 
where $X_{j i}$ are the inputs of gcods $j$ into production of good $i$. Let

$$
\begin{aligned}
V_{i}\left(K_{i}, L_{i}, p_{1}, \ldots, p_{n}\right) & =\max _{X_{i} X_{j i}}\left[r_{i} X_{i}-\sum_{j=1}^{n} p_{j} X_{j i}\right] \\
\text { s.t. } X_{i} & =F^{i}\left(K_{i}, L_{i}, X_{1}, \ldots, X_{n i}\right) .
\end{aligned}
$$

For given values of all price:, the functions $V_{i}\left(K_{i}, L_{i}, \cdot\right)$ describe, in nominal terms, the maximum net rivenue that can be earned and allocated to payment of the primary factors, capital and labor. They can therefore be used to determine the pattern of specialization, in exactly the same way that we earlier used production functions multiplied by prices. ${ }^{9}$ That is, unitvalue-added isoquants can be defined by setting $V_{i}=1$, and production will require tangency between these and the unit-isocost lines. ${ }^{10}$

With free trade, all prices are the same in the two countries, which therefore share identical unit-value-added is jquants. The argument of section 2 can be repeated and the same result obtained. Thus, the chain of comparative advantage can still be used when there are intermediate goods, so long as trade is free and the prices of primary factors are not equalized. The factor intensities used in constructing the chain represent only direct capital and labor requirements, and do not include factors that are used indirectly by being embodied in intermediate inputs. For, as long as intermediate inputs are traded freely, they need not be produced within the country in which they are used.

\section{Intermediate goods and impeded trade}

If trade is not free, however, there is a problem. It arises because the

${ }^{9}$ Note that, since $y_{i}$ is defined in nominal terms, we do not encounter the problem of defining either a natural unit for value added or a 'price' of value added, which has been a source of difficulty in the effective protection literature In particular, our construction does not require the separability assumption that has been stressed by Bruno (1973) and by Bhagwati and Srinivasan (1973). It should also be mentioned that $V_{i}$, as functions of $K_{i}$ and $L_{i}$, possess the same homogeneity and concavity properties that are assumed of the production functions, $F_{i}$. See Diewert's (1973) discussion of variable profit functions.

${ }^{10}$ In the special case, often assur ed, of fixed coefficients between intermediate inputs and final output (so that $X_{j i}=a_{j i} X_{i}$ ) the function

$$
v_{i}=\left(p_{i} \sum_{j=1}^{n} p_{j} a_{j i}\right) F^{i}\left(K, L_{i}\right)
$$

The isoquants of $V_{i}$ are then identical to the isoquants of $F^{i}$, and the unit-value-added isoquant is that for which

$$
X_{i}=1 /\left(p_{i}-\sum_{j=1}^{n} p_{j} a_{j i}\right) .
$$


position of a unit-value-added isocyuant depends on all prices and not just on the price of the corresponding final good. Thus, when a tariff on, say, good 5 in fig. 1 raises its price in $A$ above that in $B_{\text {s }}$ it does, as before, pull $A$ 's isoquant toward the origin to a position like $X_{5}^{\prime}$. But it also pushes $A^{\prime} s$ isoquants of other goods that use good 5 as an input out further from the origin than they are in country B. And this makes it impossible to infer individual relative prices from the positions of individual is oquants in the two countries as was done kefore. The same problem arises if prices differ due to transport costs, though for ease of exposition we will limit attention here to a tariff.

To see what can happen corsider the following special case which will suffice to provide a counterexample to the chain proposition. Suppose there are only three goods, with goods 1 and 2 acting solely as final goods and with good 3 acting only as an intermediate input to production of good 1 . Suppose further that country $B$ is so large that we can ta ie its prices as independent of trade with country $A$ and that $A$ is so capita abundant that it produces, i. free trade, only the most capital intensive good 1 . The free trade situation is depicted as the solid unit-value-added isoquants and isocost lines in lig. 2. The line $A A^{\prime}$ represents free trade factor prices in country A, which employs its entire endowment of capital and labor, $K^{A}$ and $L^{\mathrm{A}}$, in the production of good 1 at point $a$. Country $\mathrm{B}$, wit factor prices given by $B B^{\prime}$, produces all three goods using the unit-value-added isoquants, $V_{1}=1, V_{2}=1$, and $V_{3}=1$. Country A exports good 1 and imports goods 2 and 3.

Now suppose that country A levies a tariff on imports of good 3, raising its domestic price. This will pull A's unit-value-added isoquant for good 3 in

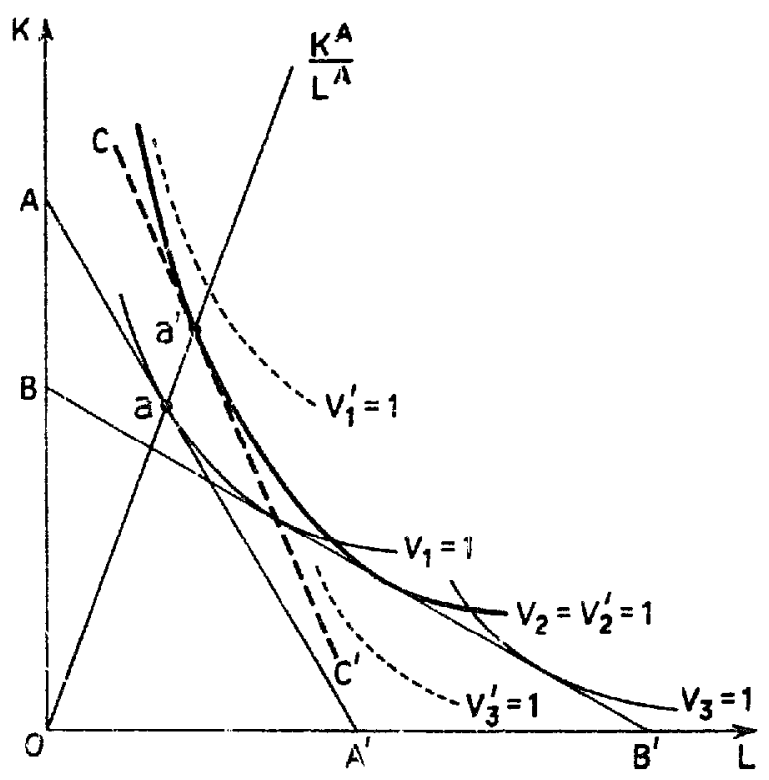

Fig. 2 
toward the origin, to a position like $V_{3}^{\prime}=1$. The isoquant for good 2 will not be affected (sirce good 2 does not use good 3 as an input), but the unitvalue-added isoquant of good 1 will be pushed out away from the origin, as additional production is required to cover the increased cost of the input of good 3 and leave a unit left over for value added. ${ }^{11}$ If the tariff is large enough and if good 3 is a sufficiently important input into production of good 1 , the new unit-value-added isoquant will be $V_{1}^{\prime}=1$ in fig. $2 .{ }^{12}$

It can now be seen from the figure that country $A$ will specialize completely in production of good 2, at point $a^{\prime}$, with factor prices given by the line $C C^{\prime}$, since this is the only pattern of production and factor prices that can both yield zero profits and employ the factors in the ratio $K^{\mathrm{A}} / L^{\mathrm{A}}$. If both countries consume something of both goods 1 and 2, it follows that country A, with the tariff, will export good 2 ind import good 1 . The pattern of trade in these two goods has therefore b?en completely reversed by the tariff on good $3 .^{13}$

The intuition behind this result is straightforward and is reflected in the diagram. When a tariff raises the price of the intermediate good, it also makes the final good more costly to produce, and since the intermediate good is itself very labcr intensive, country A cannot reduce that cost by producing it itself. Instead, all production switches to good 2 which does not require the labor intensive, and now expensive, input of good 3.

Another way of seeing what is going on in this eximple is to look at effective rates of protection. With a tariff on the intermeciate good and none on either final good, the effective rate of pretection of industry 1 is negative. Thus, while the explicit effects of tariffs are only to tax trade, the tariff on the intermediate good has the implicit effect of subsidizing imports of, in this case, the capital intensive good.

\footnotetext{
${ }^{11}$ This may sound like a description of producers who take a loss on every unit but make it up in volume'. This need not be $t^{\prime}$ - case since there was initially a positive margin for value added, and hence a small enough input price increase will leave that margin positive. But it does point up the possibility that unit-valu :-added isoquants may not just move, but may disappear when input prices increase. This is particularly true when there is no possibility of substitution away from intermediate inputs, as in the fixed coefficients case of the preceding footnote. This possibility makes a counterexample e'ven easier to obtain, however, since it means that a tariff increase can shift all production to good 2 .

${ }^{12}$ It is cssential for the countercxample hat 'he isoquant, $V_{1}^{\prime}=1$, lic outside the line $C C$ ', which is tangent to the $V_{2}=1$ isoquant where 1 crosses the $K^{A} / L^{A}$ ray. In the figure, this requires a substantial movement of the $V_{1}$ isoquant, but this need not be the case. If giod 2 were only slightly more labor-intensive than good $1, C C^{\prime}$ would lie very close to $A A^{\prime}$ and a small movement of the $V_{1}$ isoquant would suffice.

${ }^{13} \mathrm{I}$ am indebted to Jagdish Bhagwati for suggesting this construction of the counterexanple. which is more direct than was used in an earlier version of this paper. The earlier consiruction drew upon a result of Batra and Casas (1973) who showed that a nontraded intermediate good of extreme factor intensity can cause the Heckscher--Ohlin theorem to be violated. Thus, if we begin, as in this example, with the theorem holding under iree trade, a prohibitive tariff on an intermediate good can reverse the pattern of trade.
} 
The counterexample of this section shows that a ranking by capital intensities cannot suffice to determine trade. ${ }^{14}$ But more importantly, it shows that a ranking by any other criterion must fail as well. In the example, any ranking that places all of $A^{\prime}$ 's exports above all of A's imports with free trade will fail to do so when a tariff is applied. For good 1 has changed from an export to an import and good 2 has done just the reverse.

\section{Many countries}

Analysis of the free trade cases, both with and without intermediate goods, extends readily to the case of many countries, though naturally cne cannot expect a single division of the chain of comparative advantage to delineate correctly the trade of all countries. Since the analysis is similar to what has gone before, it will be left to the reader to imagine or draw the appropriate diagrams. Simply insert, as in fig. 1, the unit isocost lines for all countries. World prices - common to all couniries - must then give rise to unit-value (-added) isoquants that are tangent to the outer envelope of all of these isocost lines. Each country will then produce and export only those goods with isoquants tangent to its own isocost line, the intersections of which with adjacent cost lines therefore pro ide uppor and lower limits on the factor intensities of its exports.

Thus, the chain if goods ranked by capital intensity is broken into segments, one for each country, and the segments are ordered identically with the relative capi 1 abundance of the countries. As in the two-country case, a djacent segmeni; may con ain one good in common, if the isoquant for such a borderline good happens to touch two countries' isocost lines in the manner of good 4 in fig. 1 . Otherwise the division between segments of the chail occurs between goods. Each country must export all goods which appear only in its segment of the chain and must import all goods which do not appear in its segment. Borderline goods may be exported by either or both of the countries in whose segments they appeat. It follows that each of a country's exports must be at least as capital intensive as each of the exports of all less capital abundant countries and at least as labor intensive as each of the exports of all less labor abundant countries.

This conclusion, however, is extremely sensitive to the assumption of free trade. Even without intermediate goods, impediments to trade can drastically alter the pattern of trade.

To see his, return to the two-country configuration of fig. 1 and add a tiny ihird country, $\mathrm{C}$, with a factor endowment ratio lying between the ratios

\footnotetext{
${ }^{14}$ Note that direct-plus-indirect capital intensities do not work either. For when the intermediate good in ou: example was traded freely, then good 2 was imported even though it may be the most capital intensive on the direci-plus-indirect basis.
} 
employed by $A$ and $B$ in industry 4 . With free trade, such a country will specialize completely in production of good 4, exporting it in exchange for imports of all other goods. Now suppose, however, that it levies a large tariff on imports of the most capital intensive good, 1. The tariff will raise the price of good 1 in $\mathrm{C}$, pulling its unit value isoquant in towards - and past $C$ 's uni isocost line. Country $C$ will begin production of good 1 and the relative wage in $\mathbf{C}$ will fall. However, good 1 is so capital intensive that much of it cannot be produced with the factors available in $C$ and, if demand is also fairly inelastic, imports of good 1 will continue. Thus, there is nothing to prevent a further increase in the tariff from raising its price still more, to bring its unit-value isoquant inside $B B^{\prime}$. When that happens, a new isocost line must appear in $C$, tangent only to isoquants of goods 1 and 6 . Production of good 4 (C's original export good) ceases entirely and production of good 6 begins instead. And good 6 must also be exported, siuce good 1 cannot be, and imports of goods $2,3,4$, and 5 must continue. Thus, country $\mathbf{C}$, because of a tariff, has changed from being an exporter of a good of intermediate factor intensity to become an exporter of the most labor intensive good that there is.

it should perhaps be noted that this extreme response of the trade pattern , a tariff is only possible for a country whose factor abundance is intermediate between those of other countries. This explains why this result was not possible in the two-country case.

\section{Conclusion}

It would indeed be useful if we could construct some ranking of commodities, by some criterion, which would enable us to predict the pattern of trade, even if only in the sense of saying that each of a country's exports must lie higher on this list than each of its imports. I have shown that such a ranking is possible in certain cases. But it is impossible both in Bhagwatis 'not unimportant' case of factor price equalization and in the obviously important case of positive trade impediments and intermediate goods. This does not mean, however, that trade theorists should abandon the HeckscherOhlin theorem or the Law of Comparative Advantage. What it does mean is that we should search for alternative statements of these propositions that will retain their validity and still tell us something useful about the pattern of trade in the real world.

One such formulation has been developed, as a statement about the "factor content' of trade. Vanek (1968) showed that, under certain assumptions, the factor content of a country's trade can be inferred from a chain of factor endowment rankings, very much like the chain of comparative advantage in 
trade of goods discussed here. ${ }^{15}$ The assumptions used to prove this result, however, include factor price equalization. It is therefore not known, yet, whether the factor content version of the Heckscher-Ohlin theorem can ba exterded to the troublesnme case considered here of trade impediments and intermediate goods. ${ }^{16}$ This is an importan issue, since it was implicitly the factor content of trade that was the focus of Leontiefs (1954) famous calculations.

The resuit in section 5, in which an export good and an import good exchange roles, is as critical for the theory of comparative advantages as it is for the Heckscher-Ohlin theory. For it implies that no ranking of goods can suffice to determine trade, not even one based on relative autarky prices. Yet this does not mean that comparative advantage plays no role in determining the pattern of trade. Rather, the role that it does play is not as strong as the chain proposition wodd suggest. I have shown elsewhere that relative autarky prices must be nezatively correlated with net exports [Deardoiff (1977)]. The result of sectio: 5 is consistent with such a correlation, so long as the relative autarky price of good 1 is higher than that of good 2.

Finally, I would like to point out a use that has been made of the Bhagwati-Jones proposition of section 3, a use which turns out to be inappropriate in view of the result of section 5. Harkness and Kyle (1975) motivated their use of logit analysis in an empirical test of the HeckscherOhlin theorem on the grounds that the theorem predicts only the direction, not the exterit, of trade. They acknowledged Bhagwati's (1972) observation that even the prediction of direction fails if factor prices are equalized, but argued that transportation costs are such a fact of life that Bhagwati's counterexample cannot arise in the real world. Yet intermediate goods are just as much a fact of life as transportation costs. The counterexample which the two together permit can therefore not be dismissed so easily.

\footnotetext{
1 'Melvin (196') also stated this proposition for the two-factor case. Vanek's demonstration, which has bee a generalized to bilateral trade by Horiba (1974), allows for any number of iactors.

${ }^{16}$ Baldwin $(1971$, p. 130) states in a footnote that 'tariffs can weaken the pattern of indirect factor trade in a Hecksther-Ohlin model but cannot alone produce parade xical results'. It is unclear from the context, however, just what model he has in mind and thus whether this is any more thar a statement of the (later) Bhagwati-Jones proposition that was proved above in section 3.
}

\section{References}

Baldwin, Robert E., 1971, Determinants of the commodity structure of U.S. trade, American Economic Review 61, 126-146.

Batra, Ravendra N. and Francisco $\widetilde{R}$. Casas, 1973, Intermediate products and the pure theory of international trade: A neo-Heckscher-Ohlin framework. American Economic Review 63, 297311. 
Bhagwati, Jagdish $\because$, 1972. The Hecksche- Ohlin theorem in the multi-commodity case. Journal of Pe fitical Ecinomy 80, 1052-1055.

Bhagwati, Jagdish H. and T.N. Srinivasan, 1973, The general equilibrium theory of effective protection and resource allocation, Journal of International Economics 3, 259-281.

Bruno, M., 1973, Protection and tariff change under general equilibrium, Journal of International Economics 3, 205-226.

Deardorff, A'an V.. 1977, Comparative advantage and natural trade in general equilibrium, Seminar I iscussion Paper no. 83, Research Seminar in International Economics, University of Michig in.

Diewert, W.E, 1973, Functional forms for profit and transformation functions, Journal of Economic Theory 6, 284-316.

Haberler, Gottfried von, 1936, The theory of international trade with its applications to commercial policy (William Hodge \& Co., l ondon).

Harkness, Jon and John F. Kyle, 1975, Factors influencing United States comparative advantage, Journal of International Economics 5, 153-165.

Horiba, Y., 1974, General equilibrium and the Heckscher-Ohlin theory of trade: The multicountry case, International Economic Review 15, 440449.

Jones, Ronald W., 1956-57, Factor proportions and the Heckscher Ohlin theorem, Review of Economic Studies 24, 1-10.

Leontief, Wassily, 1954, Domestic production and foreign trade: The American capital position re-examined, Economia Internazionale 7, 3-32.

Melvin, James, 1968, Production and trade with two factors and three goods, American Econornic Review 58, 1249-1268.

Samuelson, Paul A., 1954, The transfer problem and transport costs: Analysis of the effects of trade impediments, Economic Journal, 264-289.

Travis, William P., 1964, The theory of trade and protection (Harvard Univeisity Press, Cambridge, Mass.).

Travis, William P., 1972, Production, trade, and protection when there are many commodities and two factors, American Economic Review 62, 87-106.

Vanek, Jaroslav, 1968, The factor proportions theory: The $n$-factor case, Kyklos 4, 749-756. 